\title{
Recognising Local Experiences for the Success of Vision 2030 in Kenya: Using Pen-Pals in Education as a Case
}

\author{
David Hallberg \\ Stockholm University Kista, Sweden \\ david.hallberg@dsv.su.se
}

\begin{abstract}
This study takes account of the everyday-life experience of a group of women in a resource-poor environment in Kenya. They are part of a group that the Kenyan Government wants to include in their investments in order to enhance social and economic equality. The overall purpose of the study is to learn about the potential impact of such investments on women in resource-poor environments in Kenya. In fulfilling its purpose the study takes into consideration (1) experiences of everyday-life among women in Lunga-Lunga and (2) maps strategies to recognise these experiences. The results of the study are expected to be fruitful as regards planning strategies that are of use for Vision 2030 and the development of Kenyan society. The study was carried out in two steps: the first consisted in participatory action research and the second was a follow-up study. To guide the study the notion of 'experience' is critical. During sessions and in letters to their pen-pals, the women express feelings regarding cultural, family, and health issues. For instance, some of the feelings experienced have arisen because the women are isolated from the larger world outside their own immediate environment and lack literacy skills. The study will be useful in planning governmental actions that strive to better recognise and educate citizens-especially women-in resource-poor environments.
\end{abstract}

Keywords: everyday-life, gender, lifelong learning, literacy, non-formal education, rural development

\section{Introduction}

The Kenyan Government is increasing its efforts across the country in order to give better opportunities for all citizens to gain access to information, obtain an education, and cope with modern global development. The Kenyan Government's plan for this development is called Vision 2030. Implementing this vision is intended to create an equal, middle-income society, one that takes better account of those environments and citizens that lag behind in enrolment; mainly those citizens living in resource-poor environments ${ }^{1}$. Vision 2030 is based upon three "pillars" as indicated in figure 1 below.

Figure 1: The pillars of Kenya Vision 2030 (Kenyan Government, 2007)

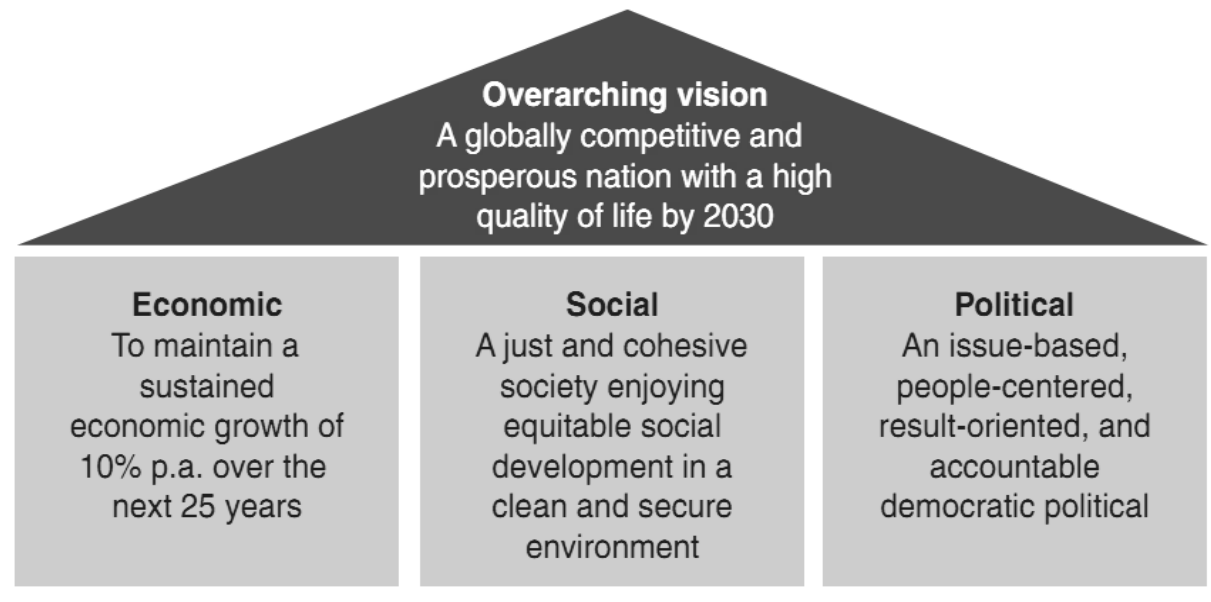

\footnotetext{
${ }^{1}$ A resource-poor environment lacks fundamental services such as hospitals, supermarkets, public schools, Internet service, public services, and similar.
} 
All Kenyan citizens should be able to identify with Vision 2030 since it is inclusive of Kenya's diverse cultures and geographic environments. Kenya's main potential lies in factors such as its people's creativity, work ethic, and education. A capacity to provide a pool of human resources ready to be absorbed into productive employment is therefore vital (Kenyan Government, 2007). The "social pillar" covers education and training strategies. In order to ensure the highest quality of training, one strategy is to encourage collaboration between public and private institutions. This also emphasises that education for all is a fundamental social value $(2007,93)$. Kenya recognises that the education and training of all Kenyans is fundamental to the success of the Vision. Education equips citizens with understanding and knowledge that enables them to make informed choices about their lives and those facing Kenyan society.

There are, however, several challenges facing Kenya (2007, 93):

- Meeting the human resource requirements for a rapidly changing and more diverse economy.

- Ensuring that the education provided meets high standards of quality, and that its contents are relevant to the needs of the economy and society.

- Raising the standards of the regions that lag behind in enrolment in order to bring then up to par with other areas.

- Improving the overall transition rates, particularly from secondary to tertiary levels.

- Creating a cohesive society imbued with a culture of hard work and efficiency, a society that also values transparency and accountability, respects the rule of law, and is concerned about the environment.

Another major concern for Vision 2030 is the fact the Government wants to use information and communications technology (ICT) in order to succeed with this project. One of its most notable solutions in this respect is the Digital Villages Project (DVP). This simple means constructing physical centres in resources-poor environments equipped with ICT, thus making provision for education, learning and retrieving societal and governmental information (e-government). A major challenge in this respect is that this sort of technology is not gender neutral (Brady, 1999, Hafkin, 2003, Marcelle, 2004, Terry \& Gomez, 2010). According to Brady (1999) women may feel uncomfortable using technology in conventional ways, whilst for men technology is an important source of political power. For instance, if women work in scientific and engineering professions, they normally have so-called lower-level jobs. Women's exit rates from these positions have also been higher than men's exit rates. Brady's "statistics suggest that technology is a contested site in part because an inhospitable work climate persists in industry for women scientists and engineers." (1999, p. 9). Furthermore, women in rural environments are more vulnerable than those in urban environments. This is not only a problem of morality and equality, but also significant as women is important actors in an ICT context, and have been shown to be of increasing significance to the socio-economic development of any nation (Dlodlo, 2009).

There are a number of ways to enhance female access to ICT in resource-poor environments. For instance by taking account of women's experiences by allowing these experiences to be shared with others, facilitating ICT access for women, creating an enabling environment for ICT in education, increasing the number of careers in ICT for and by women, and promoting local culture and language (Dlodlo, 2009). Dlodlo's study also stresses the importance of general collaboration in ICT-related activities to pursue common ICT objectives. In terms of the success or failure of Vision 2030, the philosophy of lifelong learning is central. Lifelong learning should focus upon well-being and individual quality of life (Field, 2000). The World Bank (2003) claims that lifelong learning is important for a knowledge-based economy that primarily relies upon the use of ideas rather than physical abilities. One limitation with Vision 2030 in this respect is its primary focus upon formal education. The World Bank reports namely; for a country's competitiveness in the global knowledge economy, it is essential to create opportunities for learning throughout life - formally, nonformally, and informally. Non-formal learning is referred to structured programmes not formally recognised by the national system (e.g. apprenticeship training programmes and structured on-the-job training).

Vision 2030 also mentions the importance of including women, but this could be strengthened in the vision considering the World Bank's (2003) finding: "To expand the pool of women who pursue careers in science and technology, policymakers need to ensure that careers and role models are not stereotyped as gender specific." From a European perspective, according to the European Union (EU), each citizen will need a wide 
range of key competences to cope with a modern society. EU stresses that it is particularly important to ensure that the entire population is included in such efforts, especially those groups that are particularly vulnerable because of "educational disadvantages caused by personal, social, cultural or economic circumstances" (Fontelles \& Enestam, 2006). Examples of key competences are language skills, the ability to pursue and persist in learning, individually and socially, and intercultural competence. Hence, in order to better account of women in Vision 2030 the Kenyan Government needs to recognise the experiences of those women.

The overall purpose of the study is to learn about of the potential impact of Vision 2030 on women in resource-poor environments in Kenya. In fulfilling the purpose the study (1) recognises everyday-life experience among women in Lunga-Lunga and (2) maps strategies to recognise these women's experiences. The results of the study may be expected to be fruitful in planning strategies that are useful for Vision 2030 and social development in Kenya.

Context: For this study, I have chosen as an entry point Project Africa (http://www.projectforafrica.org/), an NGO that operates in various counties of Kenya. This article focuses upon its work in Lunga-Lunga, Kwale County. According to Project Africa, Lunga-Lunga is strategically located at the border to Tanzania. One of the main crossings to Tanzania goes via this area. The area also suffers heavily from illiteracy and sexual transmitted diseases (STD). Project Africa is striving to empower women in resource-poor environments with informal and non-formal education. Project Africa, with headquarters in Sweden and Kenya, is created on a vision that "is carved from a background of the need to empower women and girls in rural Africa"(Project Africa, n.d) Its educational programme is referred to as Women's Academy.

According to the founder of Project Africa (said in 2010), the educational programme is currently promoting the increased use of computers with Internet capacity in order to enhance interaction and socialisation with other women globally. This is done using social networking sites (SNS: s), for instance. An SNS is a kind of digital, social community that allows the user to move from an individual physical experience to a collective social experience (Yoo, 2010). Another way in which Project Africa achieves its goal is by teaching women handicrafts, farming, English, digital literacy, and by spreading awareness of STDs. In the literacy classes the project employs not only traditional media (e.g. pen and paper) and ICT applications (e.g. SNSs), but one of its foremost teaching aids is the use of pen-pals (referred to by Project Africa as rafiki) in order to learn English. These pen-pals mainly live in Canada, USA, and UK.

The notion of experiences: The notion of "experience" has a particular role in the study. Vygotsky (1978) suggests experiences as physical tools (e.g. computers) and psychological tools (e.g. language), being tools that touch upon 'existence' 'reality' and 'being', all difficult to define (Raju, 1957). This notion on tools makes language a link between external communication and internal thinking (Säljö, 2000, Hrastinski, 2009), which stands in relation to Kaipayil's $(2002,2003)$ philosophical, ontological notion on experience.

Kaipayil believes an experience is an experience of something that exists; that is something of which a person is aware, which is called 'reality'. The object of experience given may be an external object, internal feeling, a previously acquired thought (memory), or a mental image created. Kaipayil's critical ontology is a fruitful tool for mapping women's experiences in learning and in their everyday lives because of its reflective nature, its explanations, its upholding of experiences of humanity and of the realm of spiritual inwardness, and its process of inward movement. The drawback with such an emphasis however, is that an interest in human inwardness has led to a species of indifference towards the social life of people. Nevertheless, philosophy contributes empowerment and development fruitfully. For, as Kaipayil and Raju comment, biology limits its study to biological life and sociology to social life, but philosophy treats all aspects of human experience. Life and reality cannot split up; they are given to people in experience as a totality. In Kaipayil's view of philosophy, there is not just one view of everything, but there are various legitimate views, i.e. pluralism, which realistically represent everyday experiences of the world.

\section{Literature Review on pen-pals in education}

In order to revise the women sharing experiences of everyday life this study concentrates on pen-pals and content analysis of letters exchanged between the women and their pen-pals. Letter writing in education is a 
way of achieving authentic communication (Green \& Hecht, 1985, Byrd, 2010). Green and Hetch focuses on errors in letter writing between native English pupils and German pupils in a communicative task during a joint project. The study illuminates errors that caused a breakdown in communication, showing that errors of vocabulary are more frequent than of grammar. The pupils, subjects for the project, were asked who they would choose if they were to become the pen-pal of one of the German pupils. They answered they would prefer those with most accurate English. This indicates that English pupils are more interested in communicating with someone who is on the same linguistic level though someone else might arouse their overall interest. If students feel they cannot gain from writing they are likely to see letter writing as a constraint on themselves and others in their education.

Upitis (1990) contrasts differences between needing a tool and creating the need, revealing results from studies between schools in Canada, USA, and Australia, and their writing of letters using electronic mail. According to her study it is crucial to understand the impact technology has on teachers and students; for once technology has begun to be used, it is difficult to break the pattern. Upitis uncovers a study relating to email communication among students in Canada, USA, and Australia, in which students were not enthralled by the writing itself, but by the idea of communicating with a school so far away. The article also reports obstacles in sending and receiving letters because of hardware and software difficulties. This seemed to be a problem because in the case of letter writing using pen and paper, actors are willing to wait several weeks before they get feedback, something which does not apply to e-mail. This is one reason why the article concludes that electronic mail is not suitable for communicating with pen-pals, but only when other means, such as telephone or post, are unsatisfactory. Consequently, Upitis suggests, if students are to communicate with people who are strangers to them, and they also encounter obstacles along the way, it is unlikely that the content of the letters will be especially meaningful.

Nonetheless, the use of the computer as an integral part of people's lives can also assist people who otherwise would be isolated (Seo, 1999). In addition, Mahfouz (2010) shows that email exchange with native speakers can be meaningful in order to achieve a better command of the language and improve writing competency. In Mahfouz' study, 110 university students in Jordan who answered a questionnaire with 40 items participated. In order to enhance the validity of the study, some of the students were also interviewed. The study, conducted over one term, reveals that the students improved literacy skills as a result of striving to form "structured sentences with clear language functions to communicate with their [native English keypals]"

Basham (1999) has conducted study in the language ecology of a particular group; what they write about themselves, and about their home communities. In order to go about this, the article explores letters solicited from school children around the USA, written in English, to peers in Alaska and Arizona. These letters reveal how children from a rural and marginalised group locate themselves and present themselves to a stranger. It describes characteristics children emphasized to make clear to the reader (i.e. the stranger) who the writer is. For example, children seem to being over emphasising the usage of pronouns. One strategy children employed to create a "you" with whom to engage was to pose a question and then provide an answer (Basham, 1999).

\section{- Hi! How are you doing? Me fine and me I like to play basketball}

- Is it cold in Alaska? In Arizona there is a little bit of snow.

Other characteristics revealed are concerned with tribal identity, e.g. conveying in the letter from which tribe the writer is, in one way or another. Basham concludes that factors shaping what gets said in these selfintroductions written by the students to unknown peers in a different environment are mainly as follows:

- The construction of self includes mentioning tribal/linguistic identity

- Orientation with respect to place is an important factor

- Personal identity is closely tied to a sense of place and orientation to geographical features shapes personal identity in ways that those people who are urban nomads do not typically see.

\footnotetext{
${ }^{2} \mathrm{~A}$ key-pal is equivalent to a pen-pal but emphasizes the usages of computer instead of pen and paper.
} 
Previous literature on letter writing and pen-pals in education also reveals factors involved in multilingual learning. For instance, Basham stresses that the construction and presentation of one's identity in writing in a second language, which is the first language of the recipient, may function to differentiate a rural community from an urban.

\section{Methodology}

The idea is that women's sharing their stories allows the reader to enter their world (McIntyre, 2000), thus gaining insight into their possible needs and experiences, and the issues facing them in their everyday lives. The period of the case study fell during ten days in November 2009 and ten days in March and April 2010. The study was carried out in three steps. By dividing the study into three parts, a better overall picture of the context was provided. The first step was conducted in conjunction with local expertise. In carrying out the second step the knowledge from the first step could be included to obtain a more appropriate focus on the issues. During the third step, experience from the previous two steps could be tied together and the lessons could be drawn with three different perspectives as a basis: the local perspective, that of the national/government representatives, and the author's perspective. This provided a richer view of the topic than if only one of the steps had been undertaken.

Step 1: The study was set up as participatory action research (PAR). For McIntrye (2000) whose study reflects a group of young adolescents negotiating their daily lives, three main principles guide most PAR projects:

- The collective investigation of a problem

- The reliance on indigenous knowledge to better understand that problem

- The desire to take individual and/or collective action to deal with the stated problem

This step was therefore designed and set out jointly with the founder of Project Africa and a regional director in Lunga-Lunga. This was a way for to approach the women on their own terms and make sure that issues relevant to them were addressed. In so doing, the study also accounted of cultural validity (Cohen, Manion, \& Morrison, 2007). Hence, in order to understand a group of people the Kenyan Government strives to reach in their ICT investments, the study was carried out in close collaboration with local forces and indigenous knowledge, such as a joint setting of the focus of the study. According to the founder, the Women's Academy in Lunga-Lunga consists of four groups with a total number of approximately one hundred women. Three women in each group plus the teacher of each group were selected at random for two focus group sessions. This makes a total number of sixteen women the first day and twelve women the second day (because of four drop-outs) who were discussed with.

The sessions, designed as a regular class, were held in Swahili, English, and in one local language interpreted to Swahili and English, in a way that calls to mind code switching (Poplack, 1980). Before these sessions two regular classes were observed without active participation: one literacy class and one sewing class. Also one class in basic IT skills was observed in the style of active participant observation. In addition, the SNS World Pulse (http://www.worldpulse.com/) in use by the women was tried out. The women presented letters written with international pen-pals. Different letters were presented during the observed classes and the constructed sessions. In addition, letters not presented on either occasion were retrieved to be analysed. All of the women's and pen-pals' letters were written in English.

All sessions were recorded, which is a good way of ensuring that one notices mistakes made by the researcher during interviews (Levy \& Hollan, 2000).

Observations and questions put centred round the following issues:

- What barriers to communication do the women experience in their everyday lives?

- What do the women reveal in focus group sessions as major topics with their overseas pen-pals?

- How do the women among the pen-pals portray their everyday lives and community?

- What are women's experiences of the usages and needs of ICT and social networking sites as tools for education and letter writing? 
Follow-up questions referred to information already provided by the participants (Brammer, 2006). Examples of such follow-up questions were as follows:

- What experiences come with learning through the use of ICT?

- What questions are discussed among pen-pals; main subjects and themes?

- What language barriers are experienced by the rural women vis à vis international pen-pals; what these barriers mean to them/definition of the term?

- What do the women consider to be the advantages and disadvantages of multi-lingual education?

After the focus group sessions, deeper, individual conversations with five of the women from the focus groups and with two mentors were carried out. Visits to three of the women's homes were also made. Conversations may be a problem since what people say happens may differ from what actually happens (Cohen, Manion, \& Morrison, 2007). Therefore, observations, interviews, and content analysis of letters were all conducted. Drawing on Cohen et al, foci of relevance were 1) behaviour; how women conducted when reading and interpreting the letters received; 2) facts; education tools and what is actually written in the letters; 3 ) physical environment around the project and the community; 4) programme setting; resources, pedagogical principles, organisation. Although observations are said to enhance research, the subjects knew they were being observed, a factor that cannot be ignored. In this study data were analysed in order to identify different ways of experiencing barriers to learning that have an impact on everyday lives, categorise them, and map out diversities (Cohen, Manion, \& Morrison, 2007)

Step 2: I went to the public university Jomo Kenyatta University of Agriculture and the headquarters of the Technology and the National Environment Management Authority (NEMA). NEMA is the Government's principal instrument for environmental issues. Here individual conversations with one director at each organisation were conducted. The purpose was to learn more about Vision 2030 and how the Government implements the vision.

Step 3: Thirdly came the follow-up study. The purpose was to discover what had happened since the first study, and to learn this independently compared with the first step. Hence, this time the study was not designed as a PAR. This step includes involvement in the daily activities of some of the women in Project Africa (participant observations); for instance, attendance at staff meetings and classes in sewing and computer literacy; individual conversations with four women, including the director and two mentors; and observation throughout the Kawale county and the parts of Tanzania immediate to the Kenyan. In this step also 3 letters were retrieved.

\section{Results}

The results are divided into five parts:

- Excerpts from the interviews at Jomo Kenyatta and NEMA.

- A description of the organisation of Project Africa and its education programme.

- Findings from focus group interviews and letter content analysis, from letters received and sent, are summarised.

This analysis reveals the major topics discussed among the women and pen-pals. It also reveals how the women experience learning using pen-pals and ICT. This part is supported by Kaipayil's notion of experience.

- Strategies for bridging barriers to learning and communication.

- Findings from the follow-up study.

Local knowledge: The following is an excerpt from the conversations with two directors at Jomo Kenyatta University of Agriculture and Technology, Institute of Computer Science and Information Technology (JK), Nairobi and the headquarters of National Environment Management Authority (NEMA), Nairobi. The excerpt 
illuminates conversation on Vision 2030 and the importance of local knowledge in order to meet the needs of the citizens.

JK: Essentially what [the Government] hopes to do is come up with a place which people around can actually have ICT services within the villages. And then they will be able to provide services to people who live around; especially the rural people in Kenya who are farming to sell coffee.

Author: Do they have any specific time-frame?

JK: Yeah. First of all there is what we call, there's something the government create they call vision 2030; of course vision 2030 is by $2030 \ldots$ in the next two or three years something is supposed to be in one site in Kenya. The only thing is that when they went it was an ICT park identified. The land then they started arguing about it when the owner realised that the government is buying the land then a lot of people started saying "It's my land I want to sell it." So they are dealing with those kinds of politics but we expect by 2012 at least something to start with then go from that.

Author: Any particular focus upon women or is it the whole population in general?

JK: Initially there was something they had said about women let me just check. I think the one [conference] I had attended they talked of giving gender a lot of focus but there was no specific policy that there must be. There's a government policy that they are working on that says $30 \%$ is to be women they are saying they will try and achieve that it has to be $30 \%$.

JK: is part of the world necessary to provide ICT services to people in the village... but in those places [the government cannot go, it has to be you, because it's like a service, a government service. The government must really get involved very politically - to the bad and to the good - it's inevitable, it's not clear. Because we cannot go in and study, we don't have the funds for that but the government can and hope they will.

Author: In what way do you consider rural areas as in, in what way do you plan for those with regard to visions and policies?

NEMA: You are asking an important question but also you will find the issues of environmental integration are higher in urban centres than in the rural areas. So that's why they have been more of a challenge trying to deal with the issues of urbanisation in the various regions. We have education for sustainable development programme; what we call ... we call regional centres of expertise what these regional centres do is that they look at local concerns. These are poverty and livelihood issues. They document them and then they provide support. Key cases in point will be issues like "How is indigenous knowledge important to the environmental issues like we now have?"...herbal medicine for a long time was treated like witchcraft but is now becoming part of mainstream medicine because it's acceptable that herbal product are just as, probably as good may be better, than refined medicine. The people themselves document the issues that are of concern to them. So some people down there have better connections and better reach down there to the community than we have. So if I left here and went to Kakamega and started talking to people, they don't know me and they don't have that much influence with them for those local community elders use that as an entry point. They are easier to access so that's the approach we are using. So that we identify the entry point and if it's a church and community development group, whatever it is, so we partner with them. Then in that way they also partner with the people. In that way you also minimise conflict because they have a role to play in the day to day interface with people, and therefore they don't want to see someone is jumping from here directly to the people and therefore that reason we have this thing in the Transmara and Narok about two month back and you find that the entry point into the community there is very difficult unless you get the right platform. Because there those people they trust so it if they get them into from the source to them it's credible information.

Author: How do you reach the women?

NEMA: Not just women there are very many marginalised groups; they are women and we found also in those areas they don't want to touch people with disabilities. You know when you walk around for two days you don't see anyone but they're there, so it is to deal with these community leaders. Community leaders are both wheels and fears. We have focused group discussions where our experts here who ladies have a chance to talk to other ladies so it is not me because I was told that it's quite a problem there and people see me talking to a 
lady so that's the approach. The structures are in place to try and get all the voices on the table so that when all decisions are made they are not taken out.

Organisation of Project Africa: Project Africa uses what it refers to as advisors, who seem to have a more central role than other staff in the project, but without being physically present. This was noticeable by telephone and email conversations among them and directors. Regional directors have both administrative and operational responsibility. This means they work about ten to twelve hours a day, often more than five days a week. Examples of tasks are planning of lessons, managing and distributing work among staff and mentors, recruiting pen-pals, and sending and retrieving post and mail from women and pen-pals.

Figure 2: Organisation of Project Africa

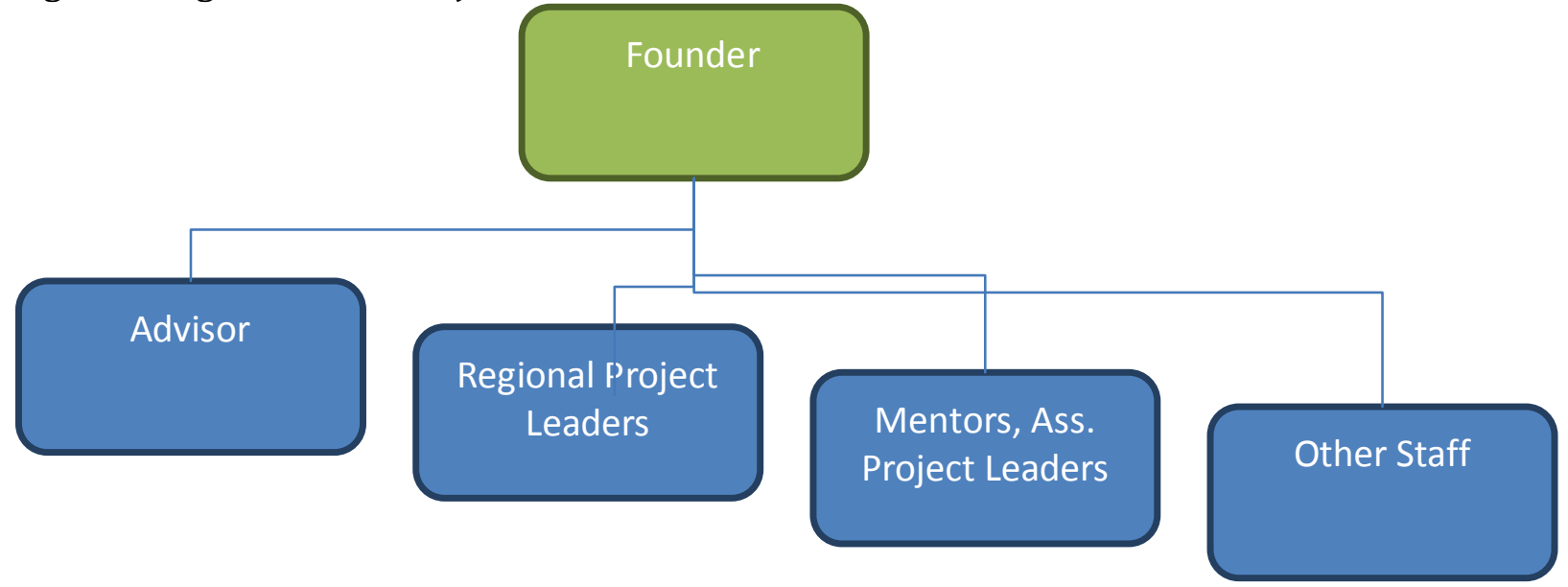

Mentors, many of whom come from Sweden and Norway, are recruited by Volontärbyrån (http://www.volontarbyran.org/), a Swedish organisation that works with NGOs to recruit mentors for nonprofit missions. According to an email from Volontärbyrån, approximately eighty percent of money received goes directly to the organisations. When mentors are looking for a place they have a chance to give details of preferred location and working area. Assistant project leaders then match mentors with adequate tasks and prepare a programme from them to follow during their stay. Tasks performed by the mentors are usually to do with education or agriculture. Project Africa also has staff working in the kitchen, in charge of surveillance, or transportation.

Organisation of the educational programme: A primary motivation for starting a project or programme such as the Women's Academy is to integrate all the nation's citizens into Kenyan society no matter where they happen to be located. The founder of Project Africa describes this as empowerment, in that learning the official language is one way of getting empowered. At the time of this study, Project Africa heldsewing, literacy, and computer classes.

\section{Figure 3: Classes in literacy, sewing, and computer (Photo: David Hallberg 2009/2010}

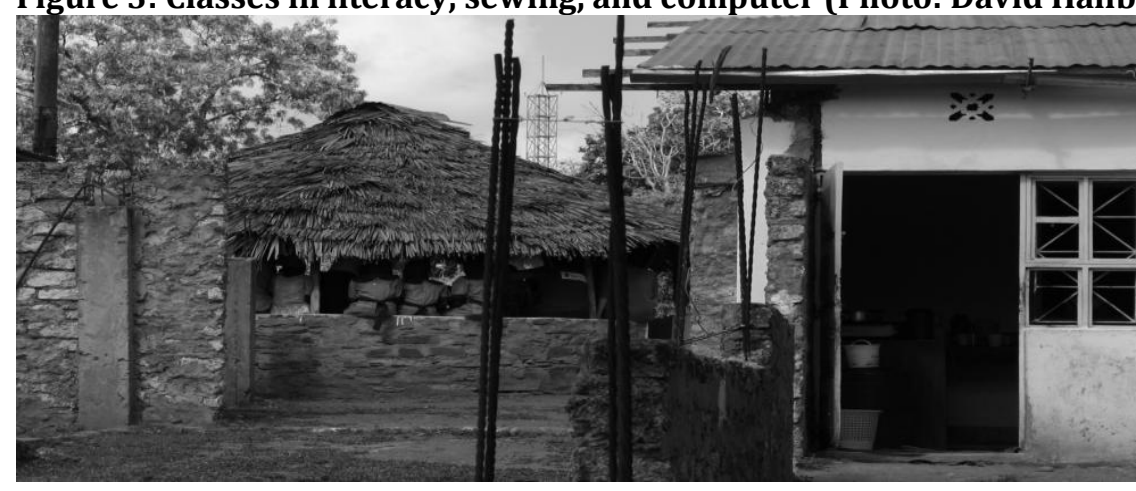




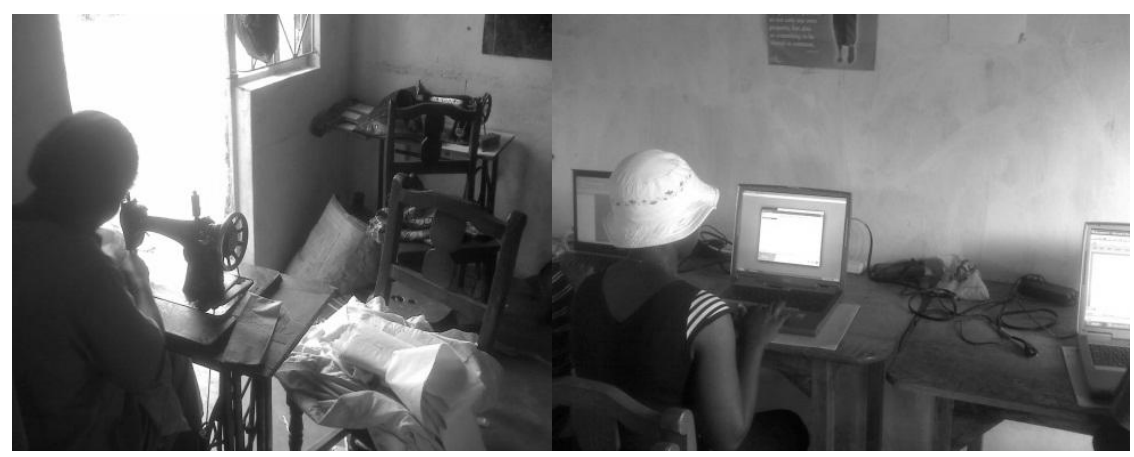

In order to support its educational programme in literacy the Women's Academy employs WorldPulse (http://www.worldpulse.com/). World Pulse is a social network, with its roots in the United States, that communicates global issues as seen through the eyes of women. On this site, Project Africa has created a group to empower women with literacy skills and build global friendships. It helps women communicate in English. The group is known as the Rafiki Club (http://www.worldpulse.com/pulsewire/groups/6627). The founder stresses the following about the group: "We recruit women from all over the world to write letters to women in Africa and share cultural diversity and languages...The Rafiki Club is a programme that complements their Adult education literacy programme...When a woman in Kenya receives a letter from her Rafiki, she gets a chance to read. When she replies to the letter she gets a chance to write."

It is said by the founder that while the Rafiki programme offers women an opportunity to learn by socialising and telling their own stories, Project Africa's educational programme is limited by its lack of a structured curriculum to follow which would also ensure assessment of progress in acquiring language skills by the participating students.

\section{Figure 4: Project Africa has created The Rafiki Club on World Pulse.}

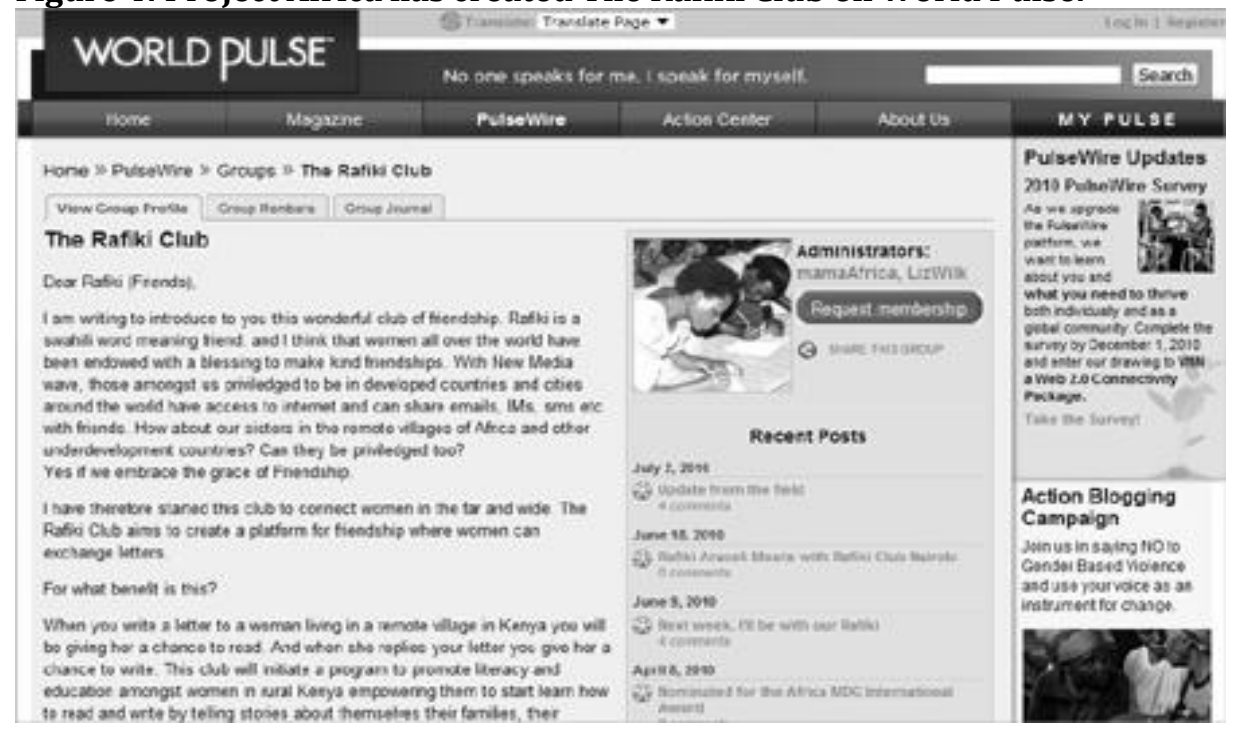

The Rafiki Club has merged the use of the traditional epistolary mode of communication with the use of the Internet to ensure that information and education can reach even the remotest parts of Africa, such as a village likeLunga-Lunga. The Rafiki Club recruits women from other countries into a letter writing exchange programme that allows pen-pals to communicate with women from the Women's Academy. Rafiki Club is employed to a) recruit pen-pals; b) discuss issues regarding the situation of women in general. However, the Rafiki Club does not primarily use digital tools for writing letters among pen-pals, but these letters are primarily handwritten. 
Women's pen-pals live mainly in the United States, the United Kingdom, Canada, and Australia. Before the use of SNS, Women's Academy corresponded by collecting the women's production of handwritten letters, and either sending them by regular post or scanning them to send using e-mail at a largercenter in the city of Mombasa. For the past year and half, Project Africa started using the Internet, including Web 2.0 on own computers at the Lunga-Lunga center. This meant that women could sometimes communicate more flexibly with their overseas pen-pals at a reduced cost as a complement to pure letter writing. This also meant that Project Africa now can combine pure literacy classes with computer classes.

Regarding the usage of overseas pen-pals in gaining literacy skills and learning English, voices by women and mentors have been raised against the fact that a majority of the pen-pals represent what is termed the Western world, wondering why African pen-pals have not been chosen and why it would be difficult to write among English speaking females across Kenya or Africa.

Letter writing and content analysis: The Women from Women's Academy mainly are in the age bracket thirty to sixty-five years. Reading the profiles of women's pen-pals, it is obvious that many of them have experiences from many countries and continents including Africa and Kenya. Few of them have a command of Swahili. It was revealed by the founder and by women during focus group sessions that Women's Academy strives to make women maintain their tribal language jointly with Swahili, while learning English. The tribal language is important; it displays culture and tells something about the person's heritage. Nevertheless, Swahili is important not only to bring all women from different language groups together, but also to maintain communication with people across the country. English is important for succeeding in business, as well as for sharing in news, media, and societal information.

A typical literacy class is designed around letter writing and reading. This means, women have the opportunity to discuss received and sent letters. The following is an example from one class where women present those letters. All letters among women and pen-pals are written in English.

Figure 5: An early letter sent by a woman from Women's Academy to her pen-pal

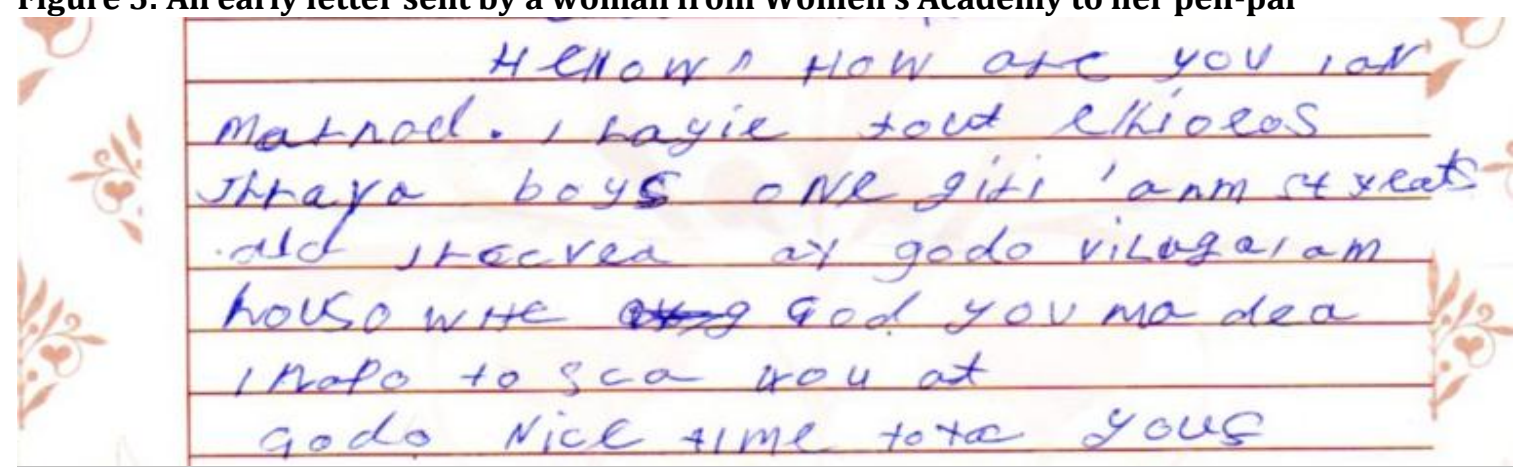

A woman brings her received letter, reads it in English and translates it to Swahili. The women together scrutinise its content from different aspects and perspectives; its literal meaning as they interpret it, and what they think was the sender's initial meaning. They discuss, using Swahili, English, and tribal languages, what would be the appropriate interpretation in different languages and for different people; or as one woman says: "If a woman prefers using her tribal tongue instead of Swahili, she does it, getting somebody to translate to Swahili if she is not able to do it."

One example of what women discuss is the Swahili word "sukumawiki," meaning cole (cabbage) in English. Understanding 'sukumawiki' is to understand the term and grasp the concept expressed by it. That is, understand it as a vegetable, a dish, and a cultural or geographical choice for people. In the discussion on sukumawiki, one argument for not translating to English is that this would make it less understandable for a majority living in Lunga-Lunga, and would not express enough.

'Independence' is another concept the women discuss to ascertain whether or not they can agree on an applicable definition. For instance, the women agreed that the role of a woman is to get a husband, and give 
birth; the role of a mother is to take care of family and household, work in connection with the home, and the production of more children. The women agree that a larger degree of independence would be good, such as being given the option not to work in the home, but to share such chores with the husband. The question that followed from this was whether such a woman still would be a "real" mother. They concluded that terms and concepts discussed in English, Swahili, and the tribal tongues differed depending on the language and interpreter. From this the women concluded that languages are important to understand other communities than their own. In conclusion, during classes the women devoted a lot of time not only to the learning and interpretation of words and sentences, but also to discussing in what ways the meaning of words may differ depending on which language is being spoken and by whom. This section continues by grouping the major topics of discussion into nine groups following Kaipayil's notion of experience.

Feeling of helplessness: One major internal feeling the women express is

"not being able to communicate effectively due to high illiteracy amongst rural women compared to experts and other business people in the community."

This feeling is explained in different ways. For example, one woman adduces, with several other women agreeing:

"asense of helplessness when not being able to find out the cost of a product".

The internal feeling of helplessness is very intense among the women. This helplessness is formulated in different ways:

"not being able to buy things in stores or withdraw money from the bank".

"sense of clumsiness when using finger-or thumbprint instead of written signature".

Not only helplessness is expressed in this last quote, but also a sense of exclusion.

Feeling of exclusion: The women feel it is difficult to be informed of what is going on in the world outside Lunga-Lunga agreeing that the Rafiki tool was a kind of "information and enlightenment tool" as they called it, one which also had the potential to break down prejudices and biases. Through communicating with pen-pals from the United States, women's previously acquired thoughts or mental images created were broken down. Namely, more than half of the women explicitly gave evidence for that, as in:

\section{"I didn't think a white person should ever talk to me"}

These thoughts, which are kinds of created mental images, tell a great deal about the nature of Lunga-Lunga's appeal, which could be interpreted in at least two ways; that there are no people with western roots in this area; and there are no people with western roots that would talk to these women. The fact of being an African woman and living in a village was something that the women came back to several times in the discussion on language and barriers to communication. Another reason for the brief letter response or lack of it is difficulties in understanding the English and Swahili vocabulary used by either of the pen-pals.

Family and relationship: The concept and term of 'family' was discussed extensively. A 'family' for the women means a mother, her children, and their father, the mother being the home-maker. A family is not considered complete without these actors. The women discuss why many women from industrialised countries do not have children or have only one child; they also discussed why many women in the west do not stay longer at home to take care of family and household.

Another expression of helplessness in relationships is another effect of not being able to read and write:

"Not being aware if one's husband is cheating on you" 
Overall, the issue of men with more than one spouse or mistress is a major concern and a topic for lively discussions among the women. In this respect, two women started an intensive debate about the importance of being able to read to understand text messages or SMS sent by the mistress or the husband. In conclusion, the women exclaim, of course almost every husband cheats on his wife, and being able to read may prevent this behaviour to some extent because, as three women stated: "he cannot hide it that easily any more". In general, the topic of men unwilling to work much and of cheating husbands was frequently discussed among the women and their pen-pals. However, an individual discussion with one of the staff reveals that she would prefer living in a polygamous relationship rather than living alone, or until she finds the right man:

"It's better to have family, so it's okay if my husband has many wives."

Labour: One woman, in response to heavy jobs says, she has come from far with her baby on her back, and when she goes out to the garden to perform duties, she still has her baby on her back. If she has to go for water, she usually has her baby...

“...and through a whole day, it becomes heavier from one task to another.

Meanwhile, the man is sleeping and does not want to do heavy jobs. Another woman agrees and begins to tell about her husband who has no job. She therefore suggests that he shall take casual work and come back with at least 100 shillings (0,94 Euro, 2010-12-29) after a whole day's work (i.e. 12 hours). Once he has earned the 100 shillings, he does not do any more, regardless of the time devoted to earning the 100 shillings. Women also find it difficult to perform jobs as those who need them often lack spectacles. This, not being able to see well, make women feel helpless and excluded too as they are dependent on their husbands.

Reproductive health: In the beginning, the discussion when it came to reproductive health and related issues was careful. The founder of Project Africa explains that women normally do not talk about such issues with men. The women mention two reasons, which are culturally rooted, why women have many children; the family is not complete without children; and a couple would not need reasons to protect themselves after marriage. This is due to the fact that the women are aware of the problem with multiple partners and prostitution. One woman says that in Kenya a number of people practise polygamy. This is something we have to accept, another woman continues. The women explain this by saying that if you do not want to be alone and without a family, it is better to accept unfaithfulness and have unprotected sex:

"your husband might have other wives".

"your husband might not accept protection, and protection is something many people don't use anyway".

Another issue discussed is that of truck drivers picking up young girls. One of the major crossing points between Kenya and Tanzania goes via Lunga-Lunga. This crossing, as another woman comments, is used by male truck-drivers and other men, who stop by along the road to take a rest, and, while resting, pick up young girls.

Differences based upon race and social status: Differences based upon race and social status in terms of lack of responses to letter is another topic for discussion. One suggestion as to why this happens would be they are black and poor, according to the women. As motivation for such a statement, two women stress that during their whole life they have never seen more than the area in which they live and work, which is about $10 \mathrm{~km} 2$, making it difficult to communicate with other people. One woman comments that there are no tourists coming to see the village, and

"Foreigners do not settle down so far from the cities or beaches".

Nevertheless, one woman reports that she has seen some of the volunteers working in Lunga-Lunga, mostly women but also men, and just discovered that "there are good men too".

Different ways of conceptualising: Internal feelings arise because of different ways of understanding concepts behind different terms. For instance, several women find it difficult to conceptualise certain terms 
that the overseas pen-pals discuss. Almost all of the women have in common very little understanding of what the world outside their own community looks like. In addition, they have their own views of the meaning of certain concepts. Therefore, it would be quite difficult for some of them to understand when their pen-pals talk about how they leave their home in a car to go to the office, stopping at the day-care centre to leave their child or children. For example, as for the term of family, one of the women explains that families consist in a mother, father, and their children, and there are almost always more than two children. The role of the mother is to take care of the children and the house. Without these attributes, there would be no family. The other women agree. The women exhibit these differences by talking about knowledge gained from pen-pals. That is, the woman's role lived by their pen-pals is not the obvious role of a mother in Lunga-Lunga. Rather, a woman can decide what her role would be like, and can make decisions jointly with her husband, on equal conditions.

Infrastructure: External objects such as the lack of means of transportation are not discussed to a larger extent. However, the women agree that the government should "invest more in rural communities like this" and take a walk around the community to see what it is like. Since women need to do the labour around the house and there is no kindergarten, it is difficult to study because a learning centre can be an hour's walk away. Another concern is high postal costs. The procedure is as follows. The women write a letter by hand. The responsible manager collects the letters, then goes to Mombasa to either send them by regular physical post or go to an internet café, and scans them in order to send them as electronic mail.

Educational tool: World Pulse - The Rafiki Club: The Rafiki Club on the SNS World Pulse is experienced as a language barrier itself among the women - both positively and negatively. In a positive sense, Rafiki is a tool that makes communication in an intercultural setting possible, and thus, as one woman comments, "improves English language learning". It also helps in improving digital literacy. The capabilities of being a tool for "sharing ideas and becoming socialised" are something positive with Rafikias far as the women are concerned. From not being able to read and write, to having gained literacy skills, the women suggest that the Rafiki could also be used as a way of promoting and developing new products to raise the income for women and the organisation Project Africa. Other advantages with the teaching tool Rafiki according to the women are that it can be employed for...

"information and enlightenment, breaking prejudice/bias, globally networking, friendship - locally and globally, and sharing ideas and advices."

In a negative sense, the World Pulse site comes in English only, which makes it difficult for women to use properly. Other drawbacks are the slow or totally missing response to letters.

Strategies to bridge the barriers: The author, together with the women, discussed and illuminated strategies to bridge the barriers the women had experienced. The strategies can be divided into three groups.

Physical teaching aids: For the first group, dictionaries (English-Swahili/Swahili-English), English for beginners textbooks and storybooks are mentioned. Since the number of teachers and the access to the Internet is strongly limited, such books would facilitate learning by making it easier for the learner to learn by herself. Women also suggested improved access to pens and papers in order to be more flexible in their learning, for example by sketching and the use of paper to make rough drafts.

Digital/electrical teaching aids: The second group is concerned with software for English learning, better equipment (e.g. notebooks, stationery, computers, scanner, printer), Internet and applications for communication (e.g. e-mail, Skype), better means for socialisation and networking, mobile phones, as well as radio and Television. These things would not only enhance learning, but also serve as a means for socialisation and being informed about what is going on nationally and internationally.

Firstly World Pulse was not employed for letter writing, but as a forum through which women could socialise, learning from the stories of others. As more and more women benefit from this SNS, they may also write directly in the forum to share their knowledge and experiences. 
The women list radio stations they find useful or would like listen to, which are to be found in table 1 below. Half of the women say they have access to radio..

\begin{tabular}{lll}
\multicolumn{2}{l}{ Table 1: Radio stations discussed among the women } \\
\hline Station & Language & Details \\
\hline Baraka FM & Swahili/English & Mixed, launched as a Christian station \\
BBC & English, Swahili & News and events, has a section for Swahili \\
Kaya Kenya & English, Swahili & Music, Popular in Kwale and coastal areas \\
KBC & Multilingual & $\begin{array}{l}\text { News, national events, the Kenyan Government. English, Swahili, } \\
\text { and local languages }\end{array}$ \\
Musyi FM & Kamba & News, entertainment, Southern and Eastern provinces \\
Radio Citizen & Swahili & One of the biggest stations in Kenya \\
\hline
\end{tabular}

Elements that facilitate learning and life: In the third group, we find extra classes for better individual tuition, more regular classes, more teachers, baby-sitters, more courses in business and handicrafts, better means of transportation, interaction with women in other regions of Kenya and other countries across Africa. As more specific arrangements, the women proposed a centre in their region with facilities and services such as telecommunication, light meals, and a place for informal meetings. Since the nearest larger centre is located in Mombasa, this should help not only the women in Kwale/Msambweni, but also everyone in the region, as well as truck drivers and potential tourists.

Implementation of new educational tools: A follow-up visit was conducted in March 2010 to discuss and observe what has happened since the last time. Project Africa has invested in four notebook computers and a printer with scanning functionality. The project now sends fewer letters by regular post and handwritten letters are instead being scanned. Computer classes have grown, and a few boys are even attending classes. What used to be a strict women's academy now seems to be more of a local/regional learning centre. One of the women stresses that girls from Tanzania even attend classes to gain digital literacy skills. This means, they want to learn basic functions in word processors and programmes for making presentations and spreadsheets. Problems that have increased with increasing ICT usage are concerned with software that need to be updated, difficulties in updating virus definitions, and problems with electricity/batteries. For instance during the time observations were made two of the notebooks needed to share a power cable and another notebook encountered software failure. Overall, however, women agree to the increased number of computers make education and learning easier.

Discussion: This study was initiated as a PAR study. This made it possible to adapt the study to women's needs. Initiating the study as PAR was probably also one of the reasons why I could come as close to the women as I did. If I had chosen a more independent approach from the outset, they would probably have left out from their stories the more private and intimate parts. At the same time, this approach also made me feel somewhat limited. The follow-up study, designed independently, was therefore important.

The brief conversation I had with the representatives from Jomo Kenyatta and NEMA led me before my second study in Africa Project to be better prepared; for instance for whatever opinions they might have of me qua man or qua representative from a university. It must be admitted, however, that it would have been beneficial to conduct these two interviews before the PAR study. I would have then been better able to position my observations and questions. In its education, Project Africa considers all tribal groups and their culture and languages. For example, the learner has opportunities to discuss the meaning of words from different cultural and language perspectives. This is important in Kenya, a country with more than forty language groups. Otherwise, it would be difficult to recognise and meet the needs of the women.

Pen-pals in education: The use of pen-pals from the Western world gives the women opportunities to learn from and understand Western culture, which, however, may influence the women and cause conflict of interest among the cultures. The way in which the women gain literacy skills and learn English could be compared with employing schoolbooks that only treat the Western culture. UNESCO (2001) in its report on empowering women farmers through literacy, comments that reading material used in educational programs for rural women too often reflect the lifestyle of the authors; and this lifestyle often has nothing to do with 
that of the women. These Western influences in learning can be referred to as "post-colonialism." All though pen-pals from the West make the women learn and understand Western culture, the women will not learn about the parts of Kenya outside their local area, or about other countries around Africa. Hence, what the women need is teaching aids and media that better reflect their own situation. Otherwise those aids and media alone cannot serve for lifelong learning, and thus not be a part of Vision 2030. The women often stated that few, if any, Western people had ever talked to them, but when it comes to teaching and learning material, Western influences is what they get. This may be contradictory. All though Project Africa has made a choice here, discussions on alternative options would be relevant.

The notion of experience: The ways in which 'experiences' are illuminated calls to mind Kaipayil's four dimensions of experiences (internal feeling, external objects, previous acquired thoughts, created mental images) as fruitful in covering many aspects of humanity. Nonetheless, it is still difficult to separate clearly his four concepts from one another. Rather, they are shown to be reciprocal. This is a proof that individuals are precisely individuals whose thoughts cannot be strictly bounded by either concepts or terms in a static way. Hence, working with humans demands flexibility and a dynamic understanding of different natures and how they appear. Still I was able to divide the topic of discussion into nine groups. The topic named "reproductive health" is the one I believe I could capture because of the PAR approach. On this issue I actually obtained too much information to cover in this article, and hence this subject would be suitable for further analysis.

Women's also had needs as regard infrastructure. Infrastructure in order to facilitate transportation, Internet, telephony, and thus learning itself are integral parts of lifelong learning and Vision 2030. The ways in which ICT might be integrated in order to meet the needs of the women would be a question for stakeholders to discuss jointly with the women in resource-poor environments. This is also something NEMA stated. It is imperative to engage in research on education since it does not take only a genuine democracy for individuals to flourish (Kaipayil, 2003), not only democracy is needed, but also individuals with literacy skills; access to education is democracy. Vision 2030 intends to address some of the needs expressed by the women in Project Africa; better access to public telecommunication not only to get informed and educated, but also to socialise.

\section{Conclusion}

The overall purpose of the study was to learn about of the potential impact of vision 2030 on women in resource-poor environments in Kenya. It was achieved by (1) recognising experiences of everyday-life experiences among women in Lunga-Lunga and (2) mapping strategies to recognise these experiences. Women's experiences of everyday life as discussed among the pen-pals, categorised into nine groups are fruitful to use for Vision 2030 and in efforts for implementing a strategy for lifelong learning. Although the categories might have been different if the women had discussed with women from their own country or elsewhere in Africa and not with women overseas or with a male interviewer.

Experiences regarding the family and reproduction were central and should be followed up by more careful studies. The Kenyan Government wants to increase the use of ICT. It would therefore be fruitful to better learn in what way the Government can use ICT to teach its citizens about family- and health-related issues. Many of the strategies mapped out here have the potential to become true when Vision 2030 is fully implemented. This study also has shown that it would be fruitful for Vision 2030 to adopt more of the philosophy around lifelong learning in its strategies.

Implications for society and practice: This study has also highlighted issues of sexual and reproductive health. The women brought up these issues even though they usually do not talk to men about this - not even with their husbands. This shows that the topic is important to them. Research on this topic exists. UNICEF has produced extensive studies on the subject. See, for example, UNICEF (2011).In this respect, for the success of Vision 2030 attention needs to be paid to adolescent development with a strong focus upon sexual transmitted diseases (STDs) and the political arrangements of an environment. For, the environment can also affect the dangers of sexual behaviours well as how the target groups can best be reached with information and education (Hallberg, 2011). Hence, researchers should continue delving into these issues focusing upon adolescents and parents. 
The Digital Villages Project was mentioned earlier. Since ICT has become an important tool in the integration of the rural with the urban environments, the government should increase its efforts to integrate information and education in the health of these ICT initiatives. The government already has a strategy to implement information about STDs in formal education at university level. However, it is important that this be implemented in non-formal and informal settings as well. This study has also shown that the Lunga-Lunga Kwale district seems to be a typical area where the government or private contractors should invest in digital villages or the like. It is important, however, that such efforts be carried through with local experiences in mind.

Acknowledgement: Thanks to all the informants and Ms. Lindy Wafula, Thanks to Prof. I.K. Kulecho and Dr. Richard Boateng for advice.

\section{References}

Basham, C. (1999). Marking one's place: expressions of identity in Athabaskan student writing. Language Sciences, 21(3), 355-369.

Brady, A. A. (1999). Tinkering with Technological Skill: An Examination of the Gendered Uses of Technologies. Computers and Composition, 16(1), 7-23.

Brammer, J. (2006). A phenomenographic study of registered nurses' understanding of their role in student learning - An Australian perspective. International Journal of Nursing Studies, 43(8), 963-973.

Byrd, D. (2010). Framing, reflecting on and attending to a rationale of teaching of writing in the second language classroom via journaling: A case study. System, 38(2), 200-210.

Cohen, L., Manion, L. \& Morrison, K. (2007). Research methods in education (6th ed.). (L. Cohen, L. Manion, \& K. Morrison, Eds.) London: Routledge.

Dlodlo, N. (2009). Access to ICT education for girls and women in rural South Africa: a case study. Technology in Society, 31(2), 1-12.

Field, J. (2000). Lifelong learning and the new educational order. Trentham: Trentham Books Limited.

Fontelles, J. \& Enestam, J. E. (2006). Recommendation of the european parliment and of the Council of 18 December 2006 on key competences for lifelong learning. Official Journal of the European Union, 394/10(394), 10-18.

Green, P. \& Hecht, K. (1985). Native and non-native evaluation of learners's errors in written discourse. System, 13(2), 77-97.

Hafkin, N. (2003). Gender Issues in ICT Policy in Developing Countries: An Overview. APWIN, 5, 32-63.

Hallberg, D. (2011). The Kenyan Digital Villages Project from a Behavioural Perspective. International Conference on Advances in ICT for Emerging Regions, 2011 (71-76). Colombo: University of Colombo School of Computing.

Hrastinski, S. (2009). A theory of online learning as online participation. Computers \& Education, 52(1), 75-82.

Kaipayil, J. (2002). Critical Ontology: An Introductory Essay. Bangalore: Jeevalaya Institute of Philosophy.

Kaipayil, J. (2003). Human as Relational: A Study in Critical Ontology. Bangalore: Jeevalaya Institute of Philosophy.

Kenya ICT Board. (2010). About Kenya ICT Board. (Kenya ICT Board,) Retrieved November 20, 2010, from http://www.ict.go.ke/index.php?option=com_content\&view=article\&id=160\&Itemid=182.

Kenya ICT Board. (2011). The Digital Villages Project. Retrieved March 1, 2011, from Kenya ICT Board: www.ict.go.ke/index.php/sport/pasha/football

Kenyan Government, T. (2007). Kenya Vision 2030. The popular version. The Kenyan Government.

Levy, R. I. \& Hollan, D. (2000). Person-Centered Interviewing and Observation. In B. Russell, Handbook of methods in cultural anthropology. Walnut Creek: AltaMira Press.

Mahfouz, S. (2010). A Study of Jordanian University Students' Perceptions of Using Email Exchanges with Native English Keypals for Improving Their Writing Competency. CALICO Journal, 27(2), 393-408.

Marcelle, G. (2004). Thinking BIG to Accelerate Gender Equality and Transformation in the ICTs Arena Gender. Technology and Development, 8(1), 31-52.

McIntyre, A. (2000). Constructing meaning about violence, school, and community: Participatory Action Research with urban youth. The Urban Review, 32(2), 123-154.

Poplack, S. (1980). Sometimes I'll start a sentence in Spanish y termino en Español: toward a typology of code-switching. Linguistics, 18(7/8), 581-618. 
Project Africa. (n.d.). Our vision. Retrieved 1, 1, 2011, from Project Africa: Empowering women \& girls in Africa:http://174.122.19.250/projectf/index.phpoption=com_content\&view=article\&id=Itemid=2.

Raju, P. (1957). Being, Existence, Reality, and Truth. Philosophy and Phenomenological Research. A Quartely Journal, 17(3), 291-315.

Seo, B. M. (1999). Keypal Project in an English Writing Course. Linguistics, 7(1), 325-393.

Säljö, R. (2000). Lärande i praktiken: Ett sociokulturellt perspektiv.Stockholm: Prisma.

Terry, A. \& Gomez, R. (2010). Gender and public access computing: An international perspective. The Electronic Journal of Information Systems in Developing Countries, 43(5), 1-17.

UNESCO. (2001). Literacy - A key to empowering women farmers. Paris: UNESCO, Decision of Basic Education, Education.

UNICEF. (2011). The State of the World's Children. New York: UNICEF.

Upitis, R. (1990). Real and contrived uses of electronic mail in elementary schools. Computers \& Education, 15(1-3), 233-243.

World Bank, T. (2003). Lifelong learning in the global knowledge economy. Challenges for developing countries. Washington, DC: World Bank.

Vygotsky, L. S. (1978). Mind in society: The development of higher psychological processes. Cambridge, Massachusetts: Harvard University Press.

Yoo, Y. (2010). Computing in Everyday Life: A Call for Research on Experiential Computing. MIS Quarterly, 34(2), 213-231. 